\section{EARLY EXPERIENCE OF SPINAL INSTRUMENTATION AT NITOR, DHAKA "SPINAL STABILIZATION IS THE GOALFOR EARLY MOBILIZATION”}

Sk. Abbas Uddin Ahmed ${ }^{1}$, ASM Monirul Alam²,Ramdew Ram Kairy $^{3}$

\begin{abstract}
:
In our country spinal injury patients are mostly treated conservatively for 12 to 18 weeks. So complications of immobilization for long time are more (bed sore, UTI, respiratory infection, paralytic ilius, wt. loss and lastly psychological distress). With this in our mind spinal stabilization was done for early mobilization of the paraplegic patients to prevent complications of immobilization.Objective of this study were : to reduce pain, to early mobilize for prevention of complications of immobilization and to assess the improvement after spinal stabilization.This Randomized prospective study was conducted from May 2003 to January 2004 at Tertiary referral Orthopaedic Institute.
\end{abstract}

\section{Introduction:}

Aim of spondylodesis to restore injured spinal column to its normal previous anatomical shape and for stability. Entails easier intensive care in multiple injury, easier general nursing task to enhance physiotherapy in acute and early phases.Compared to conservative management of the injured spinal column, mobilization is effected some 21 to 39 days earlier in surgical patients, total hospitalization in tetraplegics is shortened by 5 days and by 34 to 57 days in paraplegic patients. Irrespective of the scope of paralysis, the advantages of a spondylodesis should be considered also in case of total paraplegia.Conservative management where surgery is not indicated or even contraindicated ${ }^{1}$. Spinal fixation provide stability and restore anatomic alignment in the treatment of fractures, degenerative disease, infection, tumors and scoliosis. Internal fixation to maintain anatomical position, good alignment and prevent motion as the spine fuses ${ }^{2}$. The thoracolumbar spine is inherently unstable and early operative intervention improves mobilization and rehabilitation ${ }^{3}$.Early surgery may improve neurologic recovery and decrease hospitalization time in patients with cervical cord injuries ${ }^{4}$.

\section{Materials and Methods:}

Randomized prospective study in paraplegic ward at NITOR from May 2003 to January 2004.

1. Assoc. Prof. Orthopedics, Begum Khaleda Zia Medical College

2. Asstt. Prof Orthopeadics, Chittagong Medical College.

3. Professor, National Institute of Traumatology \& Orthopaedic Rehabilitation (NITOR), Dhaka.
35 Patients- Male 27 (77.14\%) and female 8 (22.86\%).

Age- average 36 years (17 to 52) years. Most patients were in the age group of 30 to 40 years.

Most patients- 19 (54.29\%)- primary school level, 11 (31.43\%)Secondary school level and 5 (14.28\%)- higher secondary school level.

Most of them from low socio economic condition.

Spinal injury was due to fall from tree (mainly).

Level of injury was more at dorsal region (mainly at the dorsolumber junction). All the patients were operated with spinal instrumentation and bone graft for fusion.

Hospital stay- average 14 days (7 to 20) days. Most of the patients went home after removal of stitches, as they came from a long distance. Some went home earlier and removed stitches later as outpatients. Three patients took longer time to leave hospital due to suffering from post operative fever.

Follow up- 4 monthly. All the patients were made to sit on the bed side after 3 to 4 days of operation, as pain subsided.

Mode of injury and level of injury are shown in table no: I and II.

Table-I

\begin{tabular}{lccc}
\hline Mode of injury & Male & Female & $\begin{array}{c}\text { Number of } \\
\text { patients }\end{array}$ \\
\hline $\begin{array}{l}\text { Falling of heavy weight } \\
\text { from head during carrying }\end{array}$ & $3(8.57 \%)$ & $2(5.71 \%)$ & $5(14.28 \%)$ \\
of goods overhead & & & \\
Falling from tree & $14(40 \%)$ & & $14(40 \%)$ \\
Road Traffic Accident & $7(20 \%)$ & $4(11.43 \%)$ & $11(31.43 \%)$ \\
Tuberculosis of spine & $2(5.71 \%)$ & $2(5.71 \%)$ & $4(11.43 \%)$ \\
Electric Shock & $1(2.86 \%)$ & & $1(2.86 \%)$ \\
\hline
\end{tabular}

Table-II

\begin{tabular}{lccc}
\hline Level of injury & Male & Female & $\begin{array}{c}\text { Number of } \\
\text { patients }\end{array}$ \\
\hline Cervical Spine & $3(8.57 \%)$ & $2(5.71 \%)$ & $5(14.28 \%)$ \\
Dorsal Spine & $12(34.29 \%)$ & $3(8.57 \%)$ & $15(42.86 \%)$ \\
Lumbar Spine & $12(34.29 \%)$ & $3(8.57 \%)$ & $15(42.86 \%)$ \\
\hline
\end{tabular}

\section{Operative Procedure:}

Cervical- Locked bilateral fascet joint dislocation-3-Later mass fixation. 
Fracture dislocation-2-Corpectomy, fixation with plate and screws anteriorly including bone graft from iliac crest. Dorsaldislocation-Ventral body to body fixation by screw and rod with bone graft anteriorly. Fracture dislocation- corpectomy, bone graft, fixation with screw and rod anteriorly. Fracturecorpectomy, bone graft, fixation with screw and rod anteriorly. Lumber-dislocation-body to body fixation with screw and road with bone graft anteriorly. Fracture dislocationcorpectomy, bone graft, fixation with screw and rod anteriorly. Fracture-corpectomy, bone graft, fixation with screw and rod anteriorly.

Some of them posteriorly as laminectomy for decompression and fixed with pedicle screws and rod with bone graft.
Only one case of fracture dislocation of D11 and kyphosis with complete paraplegia-Pedicle substruction osteotomy and fixation with pedicle screw and VSP plate. We could achieve good lordosis.

\section{Result:}

All mobilized at early stage. Some of them from incomplete group recovered neurological deficit. Complete paraplegic patients were mobilized with wheel chair and walking aids. Atleast most of them could avoid dependency on others and could do some of their personal works. None had complications of immobilization (bed sore, respiratory infection, UTI, paralytic ilus. None had pain at the site of spinal trauma and they could move without pain.

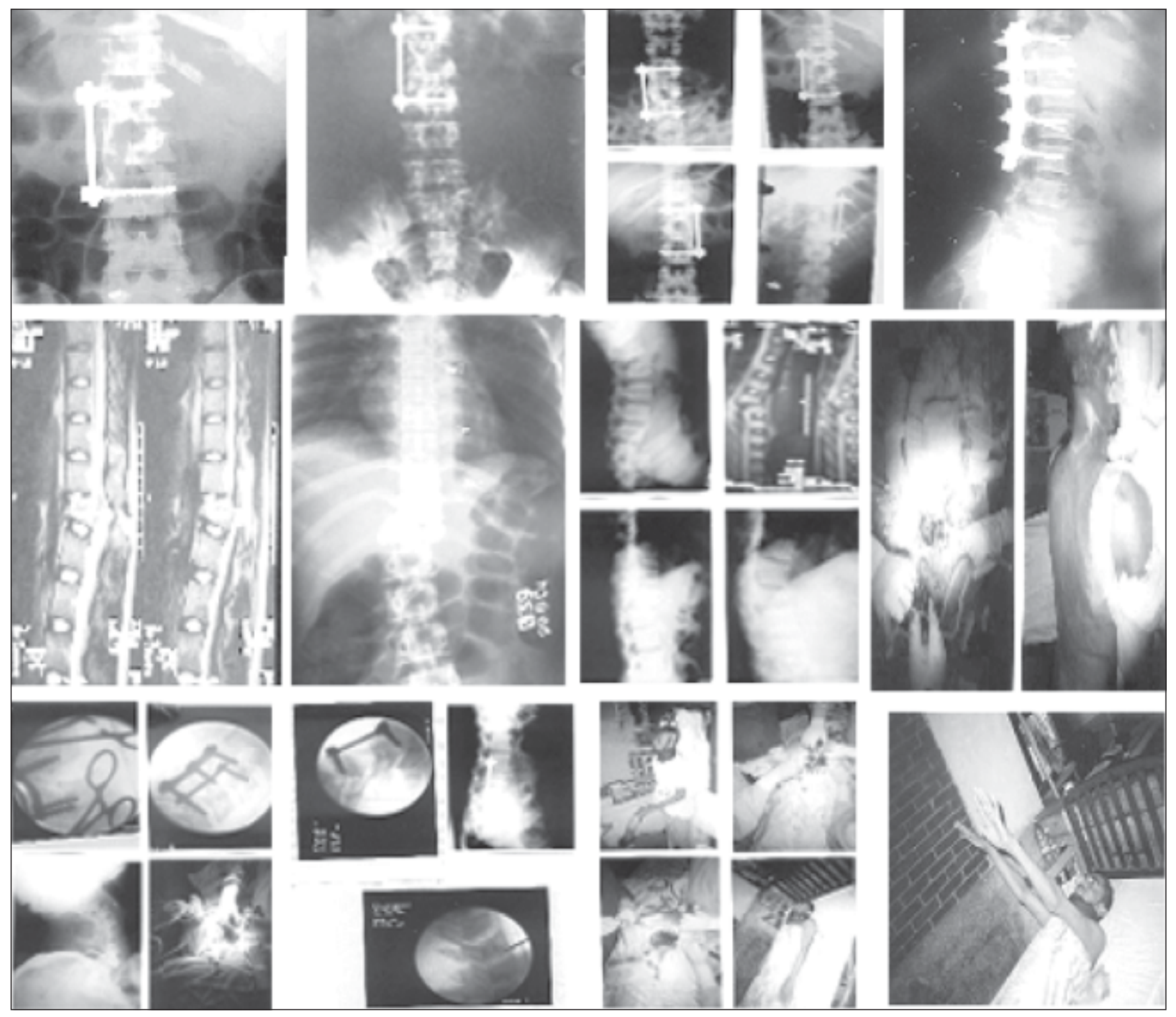




\section{Discussion:}

Bangladesh-densely populated with huge patients suffering from spinal injury due to more RTA and untrained manpower working in different places and also for undiagnosed spinal disease. In our study- we found good outcome of spinal stabilization as there was no complication of long time immobilization as with conservative treatment. To provide better management for the spinal injured patients, orthopaedic surgeons need special training in spinal surgery. Government and NGOs should come forward to improve facilities and provide equipments needed for this spine surgery and also to help poor patients during operation.

\section{Conclusion \& Recommendation:}

Early mobilization obviously prevent bad effects of long term immobilization of paraplegic patients. So early spinal stabilization (spinal instrumentation) helps in early mobilization, prevent complications of immobilization with long term conservative treatment and provide better rehabilitation of paraplegic patients.

\section{References:}

1. Meineeke FW. What has spinal stabilization contributed for the paraplegic patients? Rehabilitation (Stuttg.) 1990 Aug; 29 (3): 163-8

2. Burney RE, Waggoer R, Maynard FM. Stabilization of spinal injury for early transfer. J Trauma. 1989 Nov; 29(11): 1497-9.

3. Slone RM, MacMillan M, Montgomery WJ. Spinal fixation. Part 1. Principles, basic hardware, and fixation techniques for the cervical spine. Radiographics, 1993 Mar; 13(2):34156.

4. Slone RM, MacMillan M, Montgomery WJ. Heare M. Spinal fixation. Part 2, fixation techniques and hardware for the thoracic and lumbosacral spine. Radiographics, 1993 May; 13(3): 521-43. 